\title{
MUJER DE PALABRAS. LAS CONTRADICCIONES IDENTITARIAS EN LA VISIÓN POÉTICA DE ROSARIO CASTELLANOS
}

\author{
Gloria Vergara \\ Universidad de Colima
}

\section{RESUMEN}

La poesía mexicana del siglo xx nos muestra distintas etapas en las que la imagen de la mujer se va conformando desde variados aspectos de la cultura. La pasión, el deseo, la soledad, el rechazo social, los roles predeterminados, el reclamo y el enfrentamiento amoroso, la recuperación y exploración del cuerpo, la auto-contemplación, la conciencia de finitud, la integración con la naturaleza, la búsqueda de los ancestros, la vuelta a lo primitivo y lo sagrado, son parte de ese proceso de interiorización. En este artículo, Rosario Castellanos nos presenta esta imagen en todos los ámbitos de su obra. Nos deja en la encrucijada en la que es inminente la toma de conciencia, el darse cuenta del gran teatro del mundo en donde el papel que le toca representar a la mujer ya resulta forzado, incongruente, contradictorio. PALABRAS ClaVE: Castellanos, poesía, mujer, identidad, pasión, deseo, soledad, rechazo, cultura.

\section{ABSTRACT}

Mexican poetry of the $20^{\text {th }}$ century offers us the possibility to analize different stages in which the image of the woman is being formed according to various cultural aspects. Passion, desire, loneliness, social rejection, predetermined roles, complaint, love, recovery and exploration of the body, self contemplation, conscience of an ending, integration with nature, search of ancestors, return to the origins and the sacred, are all part of that interiorization process. This article deals with Rosario Castellanos and her way to reveal this image in all her works, leaving us at the crossroad in which taking part of consciousness is imminent, and making us reflect on women's role in our world, a role which seems forced, imposed, inconsistent and contradictory.

KEY WORDS: Castellanos, poetry, woman, identity, passion, desire, loneliness, rejection, culture.

La hazaña de convertirse en lo que se es (hazaña de privilegiados sea el que sea su sexo y sus condiciones) exige no únicamente el descubrimiento de los rasgos esenciales bajo el acicate de la pasión, de la insatisfacción o del hastío sino sobre todo el rechazo de esas falsas imágenes que los falsos espejos ofrecen a la mujer en las cerradas galerías donde su vida transcurre.

R.C. 
Rosario Castellanos ${ }^{1}$ es una de las pocas mujeres reconocidas en la tradición literaria de México. Tal vez su carácter, su impulso, la vida política en la que participó y su fuerza para enfrentar los fenómenos sociales y adentrarse en la crítica le merecieron ese lugar. Aunque algunos poetas cercanos a ella, como es el caso de Jaime Sabines, dicen:

Ella pagó muy caro dedicarse a la literatura, era francamente rechazada. Su muerte todo lo cambió; ahora cuando paso por Comitán y veo que hay un parque, un centro cultural, una cancha de fútbol y una calle que se llaman «Rosario Castellanos» me da risa. Aquella mujer ingenua, limpia, sencilla, fue víctima de todo el mundo. No pudieron salvarla sus grandes cualidades: su inteligencia, o su infinito sentido del humor, su excelente poesía ${ }^{2}$.

Y es que, como afirma la poeta, ni la mujeres veían la literatura como una profesión propia: «nadie, ni yo misma consideraba a la literatura como una profesión que pudiera ejercerla una mujer» ${ }^{3}$. Sin embargo, Rosario dedica gran parte de su obra a la búsqueda del reconocimiento de la mujer. Lucha contra las costumbres establecidas, ve la necesidad imperante de la educación femenina, rechaza la tradición y los cánones que señalan las «cualidades» de lo pasivo y lo inútil y exaltan la sumisión y la obediencia de la mujercita mexicana ${ }^{4}$. «Destaca que 'la abnegación', la más celebrada de las virtudes mexicanas, es una virtud que se ha vuelto loca,

${ }^{1}$ Rosario Castellanos nació en la Ciudad de México, el 25 de mayo de 1925, y murió en Tel Aviv, el 7 de agosto de 1974. Estudió licenciatura y maestría en filosofía en la UNAM y realizó estudios de estética en Madrid. Poeta, narradora, dramaturga, profesora, promotora cultural, y embajadora de México en Israel de 1971 a 1974. Fue becaria Rockefeller en el Centro Mexicano de Escritores (1954-1955). Obtuvo el Premio Chiapas (1958), el Premio Xavier Villaurrutia (1961), el Premio Sor Juana Inés de la Cruz (1962), el Premio Carlos Trouyet de Letras (1967) y el Premio Elías Sourasky de Letras (1972). Escribió los libros de cuentos Ciudad real (1960), Los convidados de agosto (1964) y Álbum de familia (1971); los ensayos sobre cultura femenina (1950), La novela mexicana contemporánea y su valor testimonial (1966), El uso de la palabra (serie de crónicas, 1974), Mujer que sabe latin (1974) y Mujer de palabras (publicación reciente - 2004- de artículos rescatados); las novelas Balún Canán (1957), Oficio de tinieblas (1962) y Rito de iniciación (publicación póstuma, 1996); los libros de poesía: Trayectoria del polvo (1948), El rescate del mundo (1952), Presentación en el templo (1952), Poemas:1953-1955 (1957), Al pie de la letra (1959), Livida luz (1960), Poesía no eres tú, obra poética 1948-1971 (publicación póstuma, 1974; en el presente artículo, todas las citas de poemas de Rosario Castellanos se toman de este libro, en la edición de México, FCE, 1995); y las obras de teatro: Salomé y Judith (teatro lírico, 1959) y El eterno femenino (publicada en 1975 y estrenada en 1976).

${ }^{2}$ K. Zarebska (ed.), Jaime Sabines (Algo sobre su vida). México, Ed. Karla Zarebska, 1994, p. 87.

${ }^{3}$ O. Bonifaz, Una lámpara llamada Rosario. Tuxtla Gutiérrez, Libros de Chiapas, 1984, p. 18.

${ }^{4}$ Confrontar el artículo «La abnegación es una virtud loca. La aportación de la mujer a la cultura», leído el 15 de febrero de 1971, frente al Presidente de la República, Luis Echevarría Álvarez y su esposa. 
parafraseando a Chesterton $»^{5}$. Afirma que se han valido de la supuesta incapacidad biológica de la mujer para reducirla a simple objeto de placer o a instrumento de maternidad. «No niego el papel importante que la biología juega en la constitución del ser humano, pero me niego a aceptar que las glándulas determinen un destino» ${ }^{6}$.

A través de modelos bien establecidos que infringen la regla de la pasividad como Sor Juana, Simone de Beauvoir, Simone Weil, Virginia Woolf, entre otras, Rosario se ve en la lucha diaria y entiende que el reconocimiento debe empezar por la mujer misma. Esto, sin embargo, sólo se logrará con una educación que le permita tener conciencia de sí. En «Simone de Beauvoir o la lucidez» habla de distintos tipos de mujeres: las que se acomodan en la tradición aceptando los parámetros establecidos sobre su capacidad intuitiva pero que niegan toda prueba de conocimiento, las que reflexionan sobre el papel que les confiere la sociedad respecto al mundo de la ciencia y de las artes, y «las fuertes, las obstinadas, las que desconfían de lo que se les predica, las que se sacuden el yugo que las embrutece, las libres» ${ }^{7}$. Ellas, como mujeres fuertes, viven en combate y, por eso, se convierten en emblemas de la culpa. Esto ocurre porque, como dice Rosario, «en el combate no hay vencedor. El más débil cae en la fascinación, se convierte en una cosa pasiva y opaca. Pero el gesto que su memoria de ser humano guardó de nosotros es el gesto del asesino y del culpable. Su mera presencia es una acusación» ${ }^{8}$. Y ser mujer de palabra, como Rosario, se paga con el precio de la culpa que los demás imponen.

En Mujer que sabe latín, Rosario sigue el camino de Simone de Beauvoir; va luchando por crear una conciencia sobre la realidad femenina. Critica el caso de la mujer que va a la universidad sólo hasta que consigue marido y luego se olvida de lo que aprendió para dedicarse exclusivamente al hogar. En estas circunstancias, la mujer se autoestupidiza, se vuelve hiedra, parásito, «se nutre de la vitalidad ajena». Parece que los moldes, las galerías, dice Rosario, son demasiado estrechos. Ni en su detallada revisión de la literatura, Castellanos encuentra salida. En su ensayo «La mujer mexicana del siglo XIX» afirma:

La galería de retratos femeninos no es muy abundante, muy variada ni muy profunda si nos atenemos a los textos literarios escritos en México. La mayor parte de las veces se limita a servir como telón de fondo para que resalte la figura principal: el caudillo, el hombre de acción, el que ejecuta las empresas, el que urde las intrigas, el que sueña con un porvenir mejor, el que fracasa, el que padece. $Y$ en un telón de fondo bastan unas cuantas líneas para trazar un esquema, un estereotipo: la madre, con su capacidad inagotable de sacrificio; la esposa, sólida, inamovible, leal; la novia, casta; la prostituta, avergonzada de su condición y dispuesta a las

${ }^{5}$ L. Guerrero, Palabras de espejo. La narrativa de Rosario Castellanos. Tesis de licenciatura, México, Universidad Iberoamericana, 1992, p. 54.

${ }^{6}$ O. Bonifaz, op. cit., p. 47.

${ }^{7}$ R. CAStellanos, «Simone de Beauvoir o la lucidez», Juicios Sumarios II (1966). México, FCE/CREA, 1984, pp. 19-34, p. 21.

${ }^{8}$ En «Simone de Beauvoir o la plenitud», op. cit., pp. 35-47, p. 45. 
mayores humillaciones con tal de redimirse; la «otra» que alternativamente se entrega al orgullo y al remordimiento de haber cedido a los meros impulsos del amor sin respetar las exigencias de la sociedad; la soldadera, bragada; la suegra, entrometida; la solterona, amarga; la criada, chismosa; la india, tímida9 .

Nuestra poeta se pregunta si somos así; por qué la insistencia de esos estereotipos. Debemos serlo, dice; pero, en una justa crítica a la literatura mexicana reclama los matices, el tratamiento detenido de las figuras femeninas. Admite que en su búsqueda no se encuentra satisfecha ni con lo que las mismas mujeres representan de sí en la literatura: «Nuestra búsqueda en libros escritos por mujeres no nos sacia del todo. Hay más detalles, es cierto. Pero están tan teñidos de narcisismo, de autocomplacencia que es imposible tomarlos sin el grano de sal de la ironía, de la desconfianza» ${ }^{10}$. Por ello Rosario decide enfrentarse y lo hace con las mujeres que «se nombran de acuerdo con los parámetros pre-establecidos, escritos y descritos por nuestra cultura. [...] El dilema no es simple, el conflicto radica en esta imposibilidad de definirse en libertad ${ }^{11}$. Pero Rosario también busca otras imágenes de las que fue consciente a partir de su propia situación:

muy pronto descubrí que en la misma condición se encontraban todas las otras mujeres a las que conocía: solas solteras, solas casadas, solas madres. Solas en un pueblo que no mantenía contacto con los demás. Solas, soportando unas costumbres muy rígidas que condenaban el amor y la entrega como un pecado sin redención. Solas en el ocio porque ése era el único lujo que su dinero sabía comprar. Retratar esas vidas, delinear esas figuras, forma un proceso que conserva una trayectoria autobiográfica. Me evadí de la soledad por el trabajo; esto me hizo sentirme solidaria de los demás en algo abstracto que no me hería ni trastornaba como más tarde iban a herirme el amor y la convivencia ${ }^{12}$.

En este ámbito la poeta reconoce: «Hay un momento en el que tengo que admitir que soy una criatura totalmente desvalida y en el que se me llenan los ojos de lágrimas pensando en que soy huérfana y divorciada y... [es] ese momento terrible en el que adquiero plena conciencia de mi soledad $»^{13}$. Así ve Rosario el mundo trágico que la marcó y del que emergió con la fuerza terrible de su ironía, pues — como enunció en su artículo sobre Castellanos el poeta Manuel Muñoz — «el pesimismo es también ironía, humor que encubre la muerte y que sabe erigirse aun contra sí» ${ }^{14}$,

${ }^{9}$ Mujer que sabe latín. México, FCE/SEP, 1984 (1ª ed. 1973), p. 160.

${ }^{10}$ Ibidem.

${ }^{11}$ L. Guerrero, La ironía como estrategia subversiva en la obra temprana de Rosario Castellanos. Tesis de maestría, México, Universidad Iberoamericana, 2003, p. 123.

${ }^{12}$ E. Poniatowska, "Prólogo», en J. Palley (comp.), Meditación en el umbral de Rosario Castellanos, México, FCE, 1985, pp. 7-27, p. 17.

${ }^{13}$ O. BONIFaz, op. cit., p. 51.

${ }^{14}$ M. Muñoz Aguado, «La poética de Rosario Castellanos». Cuadernos de literatura, vol. 4 (s.f.), pp. 27-35, p. 33 . 
contra su tradición y su momento. Por ello Rosario Castellanos «en lugar de declamar, reclama; en vez de complacer, arremete» ${ }^{15}$.

Rosario es un parámetro importante para las mujeres de México porque —reconoce Poniatowska — «se dijo a sí misma y al decirse definió también a muchas mujeres cuya suerte es idéntica» ${ }^{16}$. Abrió las puertas a la literatura para las que vendrían después a conformar la riqueza literaria del siglo XX. «En cierta forma es gracias a ella que escribimos las que ahora pretendemos hacerlo. Antes que ella, nadie sino Sor Juana [...] se entregó realmente a su vocación. Ninguna vivió realmente para escribir. Rosario es finalmente eso, una creadora, una hacedora de libros» ${ }^{17}$.

Como poeta, su vocación la empujó a buscar respuestas que la ayudaran a reconocerse. Empieza a estudiar Letras, pero la carrera no le satisface y se cambia a Filosofía. Allí descubre, casi al terminar la carrera, que las únicas nociones a su alcance eran «las que se disfrazaban de metáforas». Pero entonces, «no sólo estaba a punto de concluir la carrera sino que ya no escribía ni endecasílabos ni consonantes ni sonetos. Otra cosa. Anfibia. Ambigua. Y, como la cruza de especies diferentes, estéril ${ }^{18}$. En ese terreno anfibio, Castellanos ensambla de una manera prodigiosa el arte de encontrarse, pues ve en la metáfora el principio de identidad en el que confluyen humor, meditación y anclaje. En 1964, en entrevista con Emmanuel Carballo, afirma: «Si la filosofía tiene su principio de identidad, la poesía también lo tiene: es la metáfora. Para mí, la poesía es un ejercicio de ascetismo, un intento de llegar a la raíz de los objetos, intento que, por otros caminos, es la preocupación de la filosofía» ${ }^{19}$.

Rosario cuenta cómo leyó a Delmira Agustini, Juana de Ibarborou y Alfonsina Storni. Pero ella quería escribir algo diferente. «Mi problema nacía de otros orígenes y, consecuentemente, exigía otras soluciones ${ }^{20}$. Lo que deseaba era entender, entenderse. "Hasta entonces, de una manera inconsciente, yo había identificado esta urgencia con la de escribir. Lo que saliera. [...] Y su redacción me proporcionaba un alivio a la angustia como si, por un instante, me hubiera yo emancipado del dominio del caos» ${ }^{21}$. En la soledad encontró el cauce de su escritura, recurrió a la palabra para exorcizarse a sí misma de los fantasmas y monstruos que la conformaban en la diferencia: "No basta adaptarnos a una sociedad que cambia en la superficie y permanece idéntica en la raíz. No basta imitar los modelos que se nos proponen y que son las respuestas a otras circunstancias diferentes de las nuestras. No basta siquiera descubrir lo que somos. Hay que inventarnos ${ }^{22}$. Lo que Rosario

${ }^{15}$ Ibidem, p. 29.

${ }^{16}$ E. PoniatowsKa, op. cit., p. 22.

${ }^{17}$ Ibidem, p. 26.

${ }^{18}$ Mujer que sabe latín, p. 205.

${ }^{19}$ M. NaHum, Rosario Castellanos. Un largo camino a la ironía. México, COLMEX, 1984 (Jornadas 102), p. 17.

${ }^{20}$ Mujer que sabe latín, p. 204.

${ }^{21}$ Ibidem.

${ }^{22}$ Citada en A. OCAmpo, «Rosario Castellanos y la mujer mexicana». Cuadernos de literatura, vol. 4 (s.f.), pp. 37-51, p. 49. 
enuncia en sus ensayos se confirma con una congruencia impresionante en su obra poética. Aquí se dan cita una vez más la ironía y la necesidad de una autocrítica severa en la representación de la mujer, de la voz femenina que construye. Poemas como «El retorno», en Viaje redondo, nos dejan ver un ámbito social en el que se requiere una revisión del ser femenino. Surge la reflexión, como si la voz hiciera eco en el espejo para convencerse de «la realidad» en donde nadie es indispensable:

Acepta nada más los hechos: has venido

$\mathrm{y}$ es igual que te hubieras quedado o que si nunca

te hubieras ido. Igual. Para ti. Para todos.

Toma una visión colectiva de la imagen de la mujer. Ésta se ve representada por la mirada de los otros, y ya dentro de la circunstancia ella se reconoce desde fuera, en un acto reflexivo. Así, el mundo pasa bajo el lente de lo superfluo y ella encuentra la definición a través del énfasis, de la anáfora, de la reduplicación, del paralelismo: «Superflua aquí. Superflua allá. Superflua/exactamente igual a cada uno/de los que ves y de los que no ves». Rosario revela la condición de la mujer como una condición múltiple y contradictoria: víctima y culpable, superflua y frágil, ambivalente ante los deseos de su cuerpo y masoquista en su visión del matrimonio y del parto. Habla de los enfrentamientos propios del mundo femenino como la sexualidad, la maternidad y el rechazo social. Recorre los mitos y las culturas para tocar la esencia primitiva. Ve las aristas de la soledad y de la pasión, del erotismo bajo su arma liberadora: la ironía. En «Conversación entre viajeros», del mismo poemario, revela el espíritu de la mujer que por tantos siglos se ha negado a sí misma:

Me ve con reprensión, como a una impertinente que no alcanza a turbarla aunque esté adjudicándole un pasado que niega, una memoria que renunció a tener y me responde que posee una cuenta bancaria como para comprarse galerías, bibliotecas, todo lo que otros han ordenado y hecho.

Y que no necesita de ninguna otra cosa.

Hablando de identidad, la mujer representada no se quiere reconocer en el eco de la otra que interroga, de la incómoda. Lo material es un entorno que envuelve, que suple cualquiera otra necesidad, que simula toda negación, todo renunciamiento. ¿Para qué preguntarse sobre el pasado, para qué remover lo que se pone debidamente en el olvido? Con estos cuestionamientos, Rosario ataca la pasividad de la mayoría y abre el registro de la falta de conciencia sobre lo que implica y lo que debería implicar ser mujer. En el poema «Pasaporte» lleva, en una aguda estrategia, la visión burocrática a la condición cotidiana:

Mujer, pues de palabras. No, de palabra no.

Pero sí de palabras, 
muchas, contradictorias, ay, insignificantes, sonido puro, vacuo cernido de arabescos, juego de salón, chisme, espuma, olvido.

Los tonos de la prosa, de la conversación, del acontecer cotidiano se insertan con mayor fuerza en estos textos incluidos en la última parte de Poesía no eres tú. Nos dejan aspectos distintos, rachas de mujeres vistas desde dentro, recorridas como un arco iris en la complejidad de su ser. $\mathrm{Y}$ al reconocer esta complejidad, la sujeto lírica de Rosario se reconoce también en esa "hipotética» realidad que apunta como una flecha al mundo, en su referencialidad inaudita.

Pero si es necesaria una definición para el papel de identidad, apunte que soy mujer de buenas intenciones y que he pavimentado un camino directo y fácil al infierno.

Incluido en Otros poemas, «Kinsey report» es un muestrario de las distintas condiciones de la mujer. En un estilo dramático surgen las voces y se revelan en su propio discurso que acentúa la carga irónica y crítica de Castellanos. La casada, la soltera, la divorciada, la lesbiana y la señorita desfilan entre los versos. La mujer, en este poema, se va configurando claramente por la diferencia de géneros y los prejuicios sociales. La memoria se desvanece entre el pasado que debe prolongar en sus actos y el deseo natural que no puede brotar libremente.

A la casada le preocupa subir de peso y el comportamiento del marido: "Con frecuencia, que puedo predecir,/mi marido hace uso de sus derechos o,/como él gusta llamarlo, paga el débito/conyugal. Y me da la espalda. Y ronca». Ante la vida sexual se enfrenta con las culpas y miedos que le han inculcado:

Yo me resisto siempre. Por decoro.

Pero, siempre también, cedo. Por obediencia.

No, no me gusta nada.

De cualquier modo no debería de gustarme

porque yo soy decente ¡y él es tan material!

Además, me preocupa otro embarazo.

Y esos jadeos fuertes y el chirrido

de los resortes de la cama pueden

despertar a los niños que no duermen después

hasta la madrugada.

La mujer objeto, la que no puede decidir sobre su cuerpo, la que teme el qué dirán, la madre, ¿qué tanto ha ganado en el terreno en el que nos planta Rosario Castellanos? No todo es cuestión de derechos, también son las actitudes, la memoria cultural que nos conforma en esa lucha entre desplegar el placer y vigilar a los hijos de noche y de día. La mujer de hoy en México tal vez sepa más de anticoncep- 
tivos, pero las actitudes se repiten en el arquetipo que nos muestra Castellanos. Y es que en este mundo idealizado hay que no sólo cumplir con las tareas del hogar, sino estar bien dispuesta para el marido, porque si no: «El marido contempla, desde su aspecto impecable, a una mujer desgreñada, a su regreso de las rudas tareas burocráticas. ¿¿No es ese motivo suficiente para recurrir a los amigos y correr una parranda y contratar a los mariachis, para que ayuden a olvidar el fracaso? ${ }^{23}$. En este lugar de confinamiento - lo hace palpable Rosario Castellanos - la mujer ha perdido su dignidad humana. Se rechaza a sí misma; no acepta su cuerpo, las necesidades y las responsabilidades de su cuerpo, como lo enuncia la poeta en entrevista con Samuel Gordon. En su contradictoria manera de ser, la mujer comete actos repugnantes. Rosario cuenta la experiencia de ver a su madre:

Mi madre murió de cáncer. Un cáncer dolorosísimo con una agonía horrenda, y la teníamos a base de morfina. Entonces, mi papá, cuando mi mamá estaba agonizando - con la morfina, que nada más salía de un estado de sopor, para inmediatamente recibir otra dosis-, mi papá tenía gripe. Entonces mi mamá se levantaba, completamente mareada, completamente mal, descalza, agarrándose de las paredes, porque no podía ni mantenerse, para llegar hasta el cuarto de mi papá y preguntarle a él cómo había amanecido él, porque era el Señor. Entonces mi papá se daba el lujo de darle la espalda y mirar hacia la pared, y de no contestarle. Cuando yo veía esto, yo a quien quería matar era a mi mamá, porque me parecía una abyección a tal punto, tan gratuita y tan innecesaria. Pero la cara de beatitud que ella ponía cuando comprobaba que él era ese monstruo... Regresaba a la cama... sonriendo. Era el orgasmo, ir y ver que el otro era capaz de llegar hasta eso... y perdonar. La que no pudo perdonar, fui yo. Perdonar a ella. Porque, además, a primera vista, la víctima era ella. Pero cuando uno va viendo toda la elaboración, la víctima era él. Lo habían obligado a convertirse en eso ${ }^{24}$.

La soltera de «Kinsey report» no tiene el masoquismo del matrimonio; sin embargo, se gana un lugar más de confinamiento en la sociedad porque ella, dice Rosario, ni siquiera tiene las ventajas de la soledad. No la elige, la sufre, arrastra sus cadenas y cumple funciones de nana, tía que acompaña, chaperona. "Cumple una función sancionada por la sociedad, tiene que convertirse en una especie de 'comodín' de todos ${ }^{25}$. Su vida sexual recibe toda la descarga del rechazo al ser tachada de prostituta. Aunque aparentemente hoy tiene más libertad, todavía se oye el eco de sus quejas:

Al principio me daba vergüenza, me humillaba que los hombres me vieran de ese modo después. Que me negaran

${ }^{23}$ "Costumbres mexicanas», p. 28.

${ }^{24}$ S. GORDON, «Breve atisbo metodológico a la poesía mexicana de los años 70 y 80», en $S$. Gordon (comp. y ed.), Poesía mexicana reciente: aproximaciones críticas, México: UTEP/Eón, 2005, pp. 105-126, p. 38.

${ }^{25}$ Ibidem, p. 36. 
el derecho a negarme cuando no tenía ganas

porque me habían fichado como puta.

Y es que la soltera lleva la peor parte en esta mirada a la mujer, como lo deja ver "Jornada de la soltera», en Livida luz. De cualquier modo ninguna se salva ante la condición femenina. La divorciada lucha entre la diferencia de género, el deseo y el ejemplo que debe dar a sus hijas para que no caigan en lo mismo: "De cuando en cuando echo una cana al aire/para no convertirme en una histérica./Pero tengo que dar el buen ejemplo/a mis hijas. No quiero que su suerte/se parezca a la mía». La religiosa manifiesta su deseo reprimido: "Tengo ofrecida a Dios esta abstinencia/;por caridad, no entremos en detalles!/A veces sueño. A veces despierto derramándome/y me cuesta un trabajo decirle al confesor/que, otra vez, he caído porque la carne es flaca».

En todas las condiciones manifiestas en «Kinsey report» la mujer auto reprime su deseo. Por decoro, por religiosa, por desprecio al género masculino, por dar el buen ejemplo. El tránsito de la virginidad a la vida sexual en el poema deja un vacío, una desilusión. Rosario nos muestra el contraste de una esperanza romántica en la que aparentemente hay una perfecta continuidad de tradiciones y la realidad cotidiana de la mujer que lucha por reconocerse fuera de todas esas ataduras culturales. Sólo la virgen, la pura, la inocente, la casta niña que piensa en el mañana parece estar conforme en este discurso de las apariencias, los sueños y las contradicciones:

¿Qué importa la pobreza? Y si es borracho

lo quitaré del vicio. Si es mujeriego

yo voy a mantenerme siempre tan atractiva,

tan atenta a sus gustos, tan buena ama de casa,

tan prolífica madre

y tan extraordinaria cocinera

que se volverá fiel como premio a mis méritos

entre los que, el mayor, es la paciencia.

Tanto en sus ensayos, como en su poesía, Rosario ve que, más allá de la diferencia de clases sociales, la mujer está ceñida por una serie de elementos que la colocan en una situación de objeto. Ya sea para decorar la casa, como un mueble y ser exhibida en sociedad, si es rica, o destinada exclusivamente a las tareas de la casa y la maternidad, si es pobre, la mujer aspira, cuando más a la paciencia y la falta de imaginación. En «Costumbres mexicanas», la poeta dice:

Nos sentamos a esperar pasivamente que un hombre vuelva sus ojos hasta el rincón que nuestra modestia nos depara y descubra las cualidades maravillosas que nos adornan. Lo demás está previsto y sujeto a reglas bastante rigurosas. Los pasos progresivos de la aproximación del macho, nuestra esquivez convencional, nuestro disimulo del terror de perder esa oportunidad, porque nadie nos ha garantizado que se presentará otra ${ }^{26}$. 
Rosario ve, en esta radiografía de la mujer mexicana, una realidad trágicamente triste. La mujer espera a un hombre ideal que nunca llega, porque el que llega, por lo general se olvida de ella a las primeras de cambio. Ella se pierde en la espera de la telenovela en turno, lee las revistas, se le va el sueño mientras se empieza a dar cuenta de las ausencias injustificadas del marido. Aparecen los celos, el coraje, la desilusión, pero como mujer «sumisa» debe mostrar su lado cariñoso y comprensivo ante el hombre que «cansado de las tareas burocráticas» tiene que buscar consuelo en otra casa, con otra mujer que lo espera como objeto - también- de placer. En esta sociedad que nos muestra Rosario, la mujer siempre es culpable, por «incapaz», de las acciones del marido. Pero la esperanza muere al último, lo reconocemos en el sarcasmo de Rosario, cuando enuncia: «A los noventa años su marido será exclusivamente suyo (si es que ha sabido evadir los compromisos y usted ha sabido tolerar sus travesuras). Le aseguramos que nadie le disputará el privilegio de amortajarlo» ${ }^{27}$.

Rosario dramatiza las actitudes de la mujer y en una crítica directa reconoce que no es válido el sacrifico para conformar la identidad femenina. En «Meditación en el umbral», Castellanos hace un desfile de personajes literarios y de mujeres de todos los tiempos: Ana Karenina, Madame Bovary, Teresa de Ávila y Sor Juana, entre otras: "Debe haber otro modo que no se llame Safo/ni Mesalina ni María Egipciaca/ni Magdalena ni Clemencia Isaura./Otro modo de ser humano y libre./ Otro modo de ser». Pero la historia de la mujer es la historia del mundo, es la historia de su patria, por ello adquiere tal relevancia la figura de la Malinche como la madre que da la vida y la muerte. Rosario hace de la imagen de la mujer inmersa en el teatro del mundo cotidiano un arquetipo pluridiscente, con múltiples facetas, y en éste pone a descansar el paso del tiempo, de las naciones. También en sus ensayos revisa el constructo de la mujer en distintos ámbitos de la literatura europea y latinoamericana. En Teresa de la Parra estudia Ifigenia y el miedo infundido, los prejuicios inculcados. Ve a la mujer «sumisa, domada, obediente» en la literatura mexicana, sus valores representados en el honor, la abnegación y la debilidad que resaltan constantemente, pero que no responden a lo que Rosario saca de las entrañas del conflicto femenino. En este mundo representado, en el tono dramático de su poesía, la mujer se hunde, se vuelve mañosa o se burla de sí misma para liberarse de la camisa de fuerza con la que «crece». En El uso de la palabra se pregunta cómo es posible que

a estas fechas, cuando el hombre civilizado traspasa las barreras del cosmos, la mujer se afane aún por traspasar el umbral doméstico, porque únicamente más allá de él puede tener acceso a una partícula de autonomía, a una migaja de determinación propia y de independencia, a una brizna de dignidad ${ }^{28}$.

${ }^{27}$ Ibidem, p. 30.

${ }^{28}$ P. 39. 
En el poema «El talismán», de Materia memorable, vemos la búsqueda insistente de Rosario Castellanos en la mujer que ve pasar el tiempo sin que pueda reconocerse. Busca su rostro en los antepasados, en las selvas, los bosques, sin encontrar huella.

Con paso cauteloso me arrimé al campamento de los hombres. Me vieron con esos mismos ojos que calculan el peso del ganado o la totalidad de la cosecha.

Sin hablar me pusieron un lugar en la mesa, me dieron un bocado y después la madrina me señaló el quehacer, me ordenó la faena.

Aquí estoy. Tejedora, lavandera, desgranadora de maíz y, a veces, en la noche, cuando el sueño no acude, relatora de historias.

Aquí la mujer que no ha tenido nombre ni lugar es, sin embargo, quien relata, quien cuenta, quien teje la vida de los otros. La mujer ha tenido el papel primordial en la palabra, pero se ha negado a sí misma, esperando que otros, otro, dice Rosario, el que es diferente en la tribu, le dé el nombre y le muestre el misterio y las sílabas exactas. Porque la mujer relata, pero hay alguien más que «forma las figuras de barro con las manos» de la escritura. En el sentido de la creación, a la mujer le están reservados los hijos, ellos le darán un nombre. Sin embargo, la madre que representa Castellanos entra al registro de la creación poética por necesidad, sabe que no se vive sólo para tener hijos. La mujer debe lanzar su grito para espantar el dolor que la habita. En "Entrevista de prensa», de En la tierra de en medio, enuncia:

Escribo porque yo, un día, adolescente, me incliné ante un espejo y no había nadie.

¿Se da cuenta? El vacío. Y junto a mí los otros chorreaban importancia.

Se enfrenta al mundo de la escritura como una verdadera creadora, como la mujer que ha recorrido una historia y ahora reclama la palabra también en el terreno de lo escrito. Sabe del poder de la palabra, de su fuerza expresiva: «Y luego, ya madura, descubrí/que la palabra tiene una virtud:/si es exacta es letal/como lo es un guante envenenado». Sólo la palabra le permite reconocerse en ese mundo cotidiano. Sólo la palabra le da la oportunidad de reflexionar sobre sí misma como lo hace en «Toma de conciencia» de Materia memorable:

Malhumorada, irónica, levantando los hombros como a quien no le importa, yo digo que no sé sino que sobrevivo a mínimas tragedias cotidianas: la uña que se rompe, la mancha en el mantel, 
el hilo de la media que se va,

el globo que se escapa de las manos de mi hijo.

Contemplo esto y no muero. Y no porque sea fuerte

sino porque no entiendo si lo que pasa es grave,

irreversible, significativo,

ni si de un modo misterioso estoy

atrapada en la red de los sucesos.

En la poesía de Rosario Castellanos entran referencias de todas partes para ir criticando ${ }^{29}$ el prototipo de mujer. Llegan también elementos de esa memoria natural, biológica que la registra como madre, como mujer que vive cada mes el desgarramiento de la naturaleza. Ella no habla con la dulzura de la madre realizada. Expresa otros sentimientos de las que pocas mujeres se atreven a hablar en la poesía de aquellos momentos, como el parto doloroso y la presencia del hijo que les exige primero el cuerpo, luego la comida, el espacio. Su discurso poético de más alto vuelo se sostiene en la ironía de la que no escapa ni su propia sombra en la conformación de la sujeto lírica representada. En «Autorretrato» dice:

Así, pues, luzco mi trofeo y repito:

yo soy una señora. Gorda o flaca

según las posiciones de los astros,

los ciclos glandulares

y otros fenómenos que no comprendo.

La poesía de Rosario deja ver en esas facetas ocultas una amarga verdad que la poesía desnuda. La mujer sufre y llora por hábito, por herencia, por no diferenciarse de las demás:

Sería feliz si yo supiera cómo.

Es decir, si me hubieran enseñado los gestos,

los parlamentos, las decoraciones.

En cambio me enseñaron a llorar. Pero el llanto

es en mí un mecanismo descompuesto

y no lloro en la cámara mortuoria

ni en la ocasión sublime ni frente a la catástrofe.

Lloro cuando se me quema el arroz o cuando pierdo

el último recibo del impuesto predial.

${ }^{29}$ Laura Guerrero ha dicho en este sentido: «Para Rosario Castellanos no existe una mujer que abarque a todas, no una imagen en la que podamos identificar a nuestra abuela y a nuestra hija. Somos muchas, diversas, distintas; con esto Rosario demuestra su antiesencialismo» (México, UIA, julio 5 de 2005). 
Cuestiona «los valores» de la tradición y deja que se presente de forma natural la mujer inconstante, la que titubea ante la vida diaria y expresa: «heme aquí, ya al final, y todavía/no sé qué cara le daré a la muerte». Porque la muerte no es individual sino colectiva, dice. «Muere la generación a que hemos pertenecido; muere la memoria sobre la que dejamos grabada nuestra figura; muere el momento sobre el que actuamos ${ }^{30}$.

Rosario Castellanos nos deja una clara preocupación de la identidad femenina, del ser mujer en todos los ámbitos de su creación. Y al final del camino, con todas las contradicciones que el cruce de tradiciones impone, podemos seguir diciendo con ella:

Quizá no ahora ni mañana. Porque el ser un parásito (que es lo que somos más que unas víctimas) no deja de tener sus encantos. Pero cuando el desarrollo industrial del país nos obligue a emplearnos en fábricas y oficinas, y atender la casa y los niños y la apariencia y la vida social y, etc., etc., etc., entonces nos llegará la lumbre a lo aparejos ${ }^{31}$.

Castellanos nos deja en la encrucijada en la que es inminente la toma de conciencia, el darse cuenta del gran teatro del mundo en donde el papel que le toca representar a la mujer ya resulta forzado, incongruente, contradictorio. Curiosamente, los caminos de la palabra escrita, de la política, de la vida social comprometida parecen abrirse cuando Rosario termina su discurso, cuando muere. Pero se abren apenas para las atrevidas, para las que alcanzan a ver a lo lejos que sí hay una luz propia, que debe haberla; para la mujer de palabra, capaz de asumir sus contradicciones; para la que todavía señala a veces con el dedo castigador; para la mujer de palabra que muchos mandan, en un camino directo, literalmente al infierno.

${ }^{30}$ Juicios Sumarios II (1966), p. 53.

${ }^{31}$ Ibidem, p. 60. 